\title{
Increasing Bending Strength and Pullout Strength in Conical Pedicle Screws: Biomechanical Tests and Finite Element Analyses
}

\author{
Ching-Kong Chao, PhD, * Ching-Chi Hsu, PhD, ${ }^{*}$ Jaw-Lin Wang, PhD, $\dagger$ \\ and Jinn Lin, MD, PhD†
}

Study Design: Comparative in vitro biomechanical study and finite element analysis.

Objectives: To investigate the bending strength and pullout strength of conical pedicle screws, as compared with conventional cylindrical screws.

Summary of Background Data: Transpedicle screw fixation, the gold standard of spinal fixation, is threatened by screw failure. Conical screws can resist screw breakage and loosening. However, biomechanical studies of bending strength have been lacking, and the results of pullout studies have varied widely.

Methods: Ten types of pedicle screws with different patterns of core tapering and core diameter were specially manufactured with good control of all other design factors. The stiffness, yielding strength, and fatigue life of the pedicle screws were assessed by cantilever bending tests using high-molecular-weight polyethylene. The pullout strength was assessed by pullout tests using polyurethane foam. Concurrently, 3-dimensional finite element models simulating these mechanical tests were created, and the results were correlated to those of the mechanical tests.

Results: In bending tests, conical screws had substantially higher stiffness, yielding strength, and fatigue life than cylindrical screws $(P<0.01)$, especially when there was no step at the thread-shank junction. In pullout tests, pullout strength was higher in screws with a conical core and smaller core diameter and also in situations with higher foam density $(P<0.01)$. In finite element analysis, the maximal deflection and maximal tensile stress were closely related to yielding strength $(r=-0.91)$ and fatigue life $(r=-0.95)$, respectively, in the bending analyses. The total reaction force was closely related to the pullout strength in pullout analyses $(r=0.84$ and 0.91 for different foam densities).

Received for publication September 17, 2006; accepted April 14, 2007. From the *Department of Mechanical Engineering, National Taiwan University of Science and Technology; and †Department of Orthopedic Surgery, National Taiwan University Hospital, Taipei, Taiwan.

The devices that are the subject of this manuscript are not FDAapproved for this indication and are not commercially available in the United States.

Reprints: Jinn Lin, MD, PhD, Department of Orthopedic Surgery, National Taiwan University Hospital, No. 7 Chung Shan S. Rd, Taipei, Taiwan 100 (e-mail: jinn@ntu.edu.tw).

Copyright (C) 2008 by Lippincott Williams \& Wilkins
Conclusions: Conical screws effectively increased the bending strength and pullout strength simultaneously. The finite element analyses reliably predicted the results of the mechanical tests.

Key Words: conical screws, bending strength, pullout strength, finite element analysis

( J Spinal Disord Tech 2008;21:130-138)

$T$ he posterior approach for the treatment of spinal disorders has the advantages of less invasiveness and easier correction of malalignment. The transpedicle screw device with its adequate control of vertebral motion in each plane and its resistance to all types of load is superior to the conventional hook or wire in that it can achieve reduction and fixation with the same instrumentation, limit spinal arthrodesis to the disease segments, and provide high fixation stability for early mobilization of patients. ${ }^{1-5}$ Although the introduction of pedicle screw fixation opened a new horizon and this approach has become the gold standard of spinal fixation, it is a technically demanding procedure with potential complications. ${ }^{1,6-8}$ Failure of the pedicle screws includes breakage, and loosening can lead to loss of fixation and painful pseudoarthrosis. ${ }^{7,9,10}$ Moreover, a broken screw fragment trapped in the vertebral body is difficult to retrieve and may interfere with subsequent revision surgeries. ${ }^{11}$ Continued clinical experience with various implant designs has led to ongoing improvements to prevent implant failure, but reasons for such failure, other than initial inexperience of the surgeon, still have not been elucidated. ${ }^{7}$ We believe the conical screw with a tapering of the screw core can better resist screw breakage and loosening, as compared with the conventional cylindrical screw. However, biomechanical studies to compare the bending strength between conical screws and cylindrical screws have been lacking. Similarly, pullout studies have been inconclusive in that the results of such studies on conical screws have varied widely. ${ }^{12-16}$

In the present study, the bending strength and pullout strength of specially designed and manufactured pedicle screws with different patterns of core tapering were tested and compared biomechanically. Concurrently, 3-dimensional finite element models simulating 
the mechanical tests were created and analyzed. It was hypothesized that conical screws yield simultaneously higher bending strength and pullout strength than cylindrical screws and finite element analysis effectively predicts the results of these mechanical tests.

\section{MATERIALS AND METHODS}

\section{Structures of the Pedicle Screws}

The specially manufactured, $45-\mathrm{mm}$ long pedicle screws with an outer diameter of $6.5 \mathrm{~mm}$ were divided into 2 groups (I and II) with a core diameter of 3.9 and $4.9 \mathrm{~mm}$ at the screw tip, respectively (Fig. 1). Each group comprised 5 types with different core taperings, but the other design variables (Fig. 2A) were kept constant: pitch, $2.8 \mathrm{~mm}$; proximal root radius, $0.8 \mathrm{~mm}$; distal root radius, $1.2 \mathrm{~mm}$; proximal half angle: 14 degrees; distal half angle, 25 degrees; and thread width, $0.2 \mathrm{~mm}$. The core tapering began at the screw tip in type 1 , at $1 / 3$ length from screw tip in type 2 , and at $2 / 3$ length in type 3 . The core diameter of the most proximal thread of these 3 types of screws approximated the diameter of the screw shank with no step at the thread-shank junction (Fig. 2B). The conical pattern of type 3 screws was similar to CotrelDubousset (Medtronic Sofamor-Danek, Memphis, TN). Type 4 screws were cylindrical screws with a deep step at the thread-shank junction, similar to Moss Miami (DePuy Spine, Raynham, MA). Type 5 screws were similar to type 3, but there was a small step at the threadshank junction, similar to TSRH (Danek, Memphis, TN). The conical design of each screw is described in Table 1 . All the screws were made of a titanium alloy according to the specification of American Standard of Tested Materials (ASTM) F136-96 ${ }^{17}$ (Ti6Al4V) (Carpenter Technology, Reading, PA). Titanium alloy is preferred because of its higher endurance limit, which is about 1.68 times that of $316 \mathrm{~L}$ stainless steel. ${ }^{18}$ All mechanical tests were performed on 6 new, unused screws. After each test, the failure mode of the assembly was investigated.

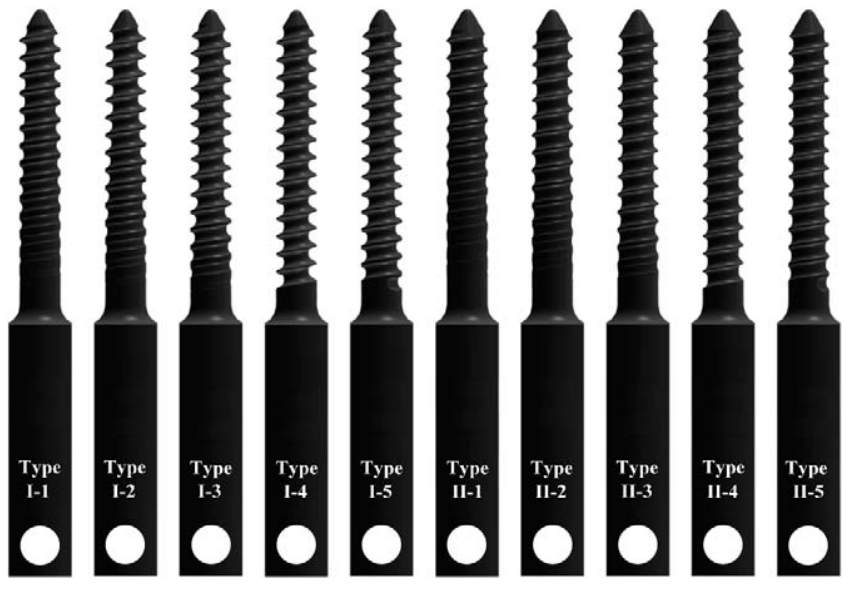

FIGURE 1. Structure of the specially manufactured pedicle screws.
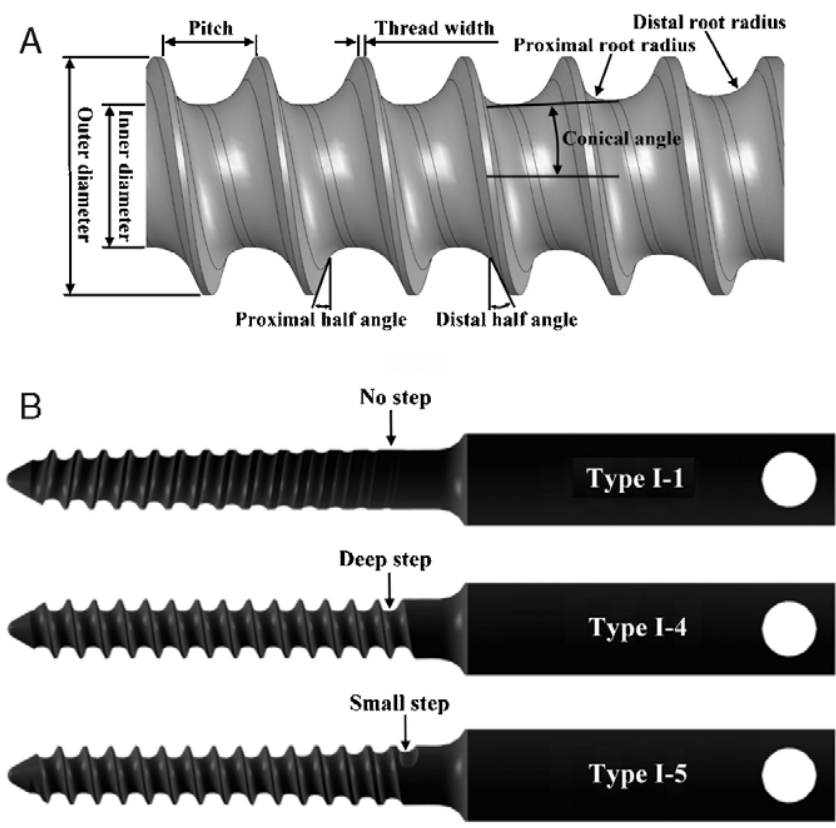

FIGURE 2. Design variables of the screws $(A)$ and 3 kinds of thread-shank junctions (B).

\section{Mechanical Tests}

\section{Bending Tests}

As reported by Fogel et al, ${ }^{19}$ a cantilever bending test can simulate pedicle screws in clinical conditions. Highmolecular-weight polyethylene cylinders (Universal Plastics, Auckland, New Zealand) with an outer diameter of $20 \mathrm{~mm}$ were used. Use of polyethylene instead of human vertebrae can eliminate the interspecimen variability and prevent deformation or breakage during mechanical loading. A fixed length of $40 \mathrm{~mm}$ of the screw was inserted through the center of the polyethylene. Then cantilever bending tests representing a worst-case scenario of the total corpectomy model were conducted on a materials testing machine (Bionix 858, MTS Corporation, Minneapolis, MN) with tight clamp of the screw cap and a vertical point loading on the polyethylene with a lever arm of $45 \mathrm{~mm}$ (Fig. 3A). First, single load yielding tests were performed in air under ambient conditions with a loading rate of $2.5 \mathrm{~mm} / \mathrm{min}$ in

\begin{tabular}{|c|c|c|c|c|c|c|c|c|c|c|}
\hline $\begin{array}{l}\text { Conical } \\
\text { Design }\end{array}$ & I-1 & I-2 & I-3 & I-4 & I-5 & II-1 & II-2 & III-3 & II-4 & II-5 \\
\hline $\begin{array}{l}\text { Conical } \\
\text { angle } \\
\text { (degree) }\end{array}$ & 1.655 & 2.481 & 4.953 & - & 2.481 & 1.018 & 1.527 & 3.052 & - & 1.527 \\
\hline $\begin{array}{l}\text { Beginning } \\
\text { point of } \\
\text { conical } \\
\text { angle } \\
(\mathrm{mm})\end{array}$ & 0 & 15 & 30 & - & 30 & 0 & 15 & 30 & - & 30 \\
\hline
\end{tabular}

— indicates cylindrical design. 

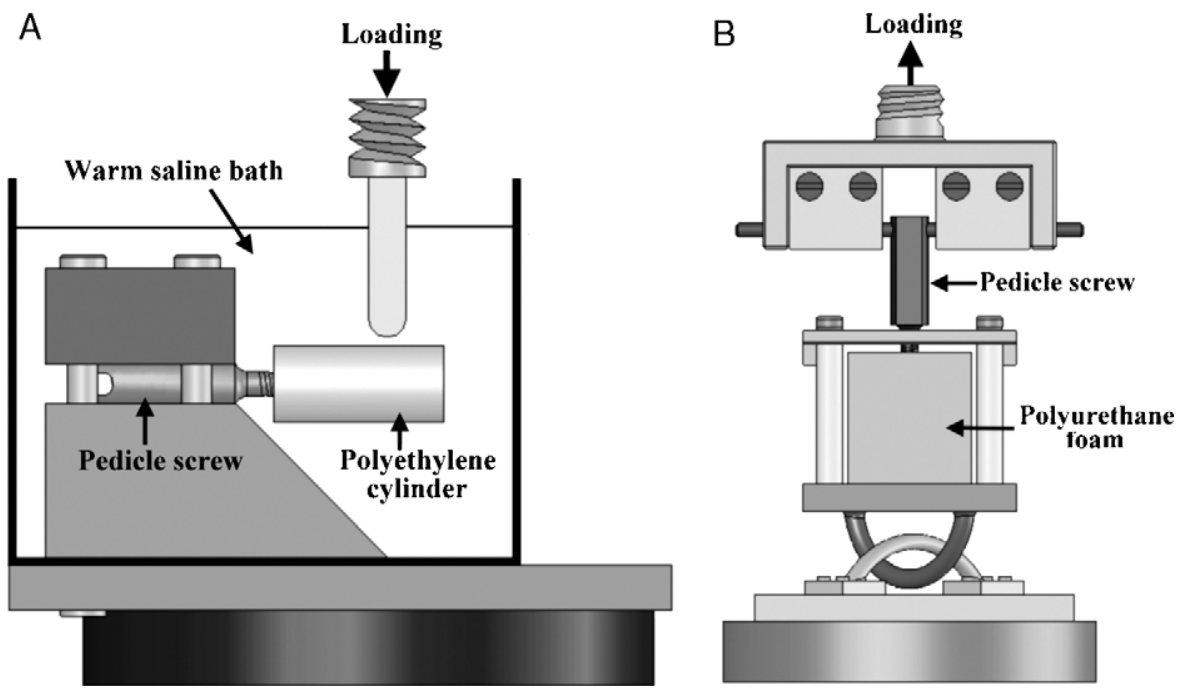

FIGURE 3. Schematic diagram of cantilever bending tests $(A)$ and pullout tests (B).

displacement control mode. The loading continued until it reached $20 \mathrm{~mm}$ to ensure plastic deformation of all the screws. The load-deformation curve was recorded. Next, with the same testing setup, sinusoidal waveform cyclic loading with a frequency of $5 \mathrm{~Hz}$ was performed with screws submerged in a saline bath at $37^{\circ} \mathrm{C}$. Two loading conditions, 400 and $600 \mathrm{~N}$, were tested with a stress ratio $\mathrm{R}$ of $10 \%$. The tests were terminated when the displacement of the actuator was beyond $10 \mathrm{~mm}$ or when the number of testing cycles was more than one million. ${ }^{9}$ The deformation of the screws and the amplitude of the loading were continuously monitored. The cyclic stiffness, deformation of the screws, and the number of cycles at failure were recorded.

\section{Pullout Tests}

Cellular polyurethane foam (Pacific Research Laboratories, Vashon, WA) conforming to the standard of ASTM F1839-9720 can prevent the widely varying results that occur in biomechanical tests using cadaver bone. ${ }^{12-16}$ Two densities of the foam -0.32 and $0.16 \mathrm{gm} / \mathrm{cm}^{3}$ with a compressive modulus of 137.5 and $23 \mathrm{MPa}$, a compressive strength of 5.4 and $2.3 \mathrm{MPa}$, and a porosity of $71 \%$ and $86 \%$, respectively-were used to simulate cancellous bones with different degrees of osteoporosis. Each screw was inserted at the center of the foam brick with a dimension of $4 \times 4 \times 6 \mathrm{~cm}$. The size of the pilot hole was the same as that of the core diameter of the screws, either 3.9 or $4.9 \mathrm{~mm}$. All the pedicle screws were inserted with a length of $45 \mathrm{~mm}$ without pretapping. The foam brick was completely seated in a fixture frame when an extraction load was applied longitudinally to the screw head at a loading rate of $5 \mathrm{~mm} / \mathrm{min}$, conforming to the standard of ASTM F1691-96 21 (Fig. 3B). The load-displacement curves were recorded.

\section{Finite Element Analysis}

Finite element analyses of the pedicle screws were conducted with the use of commercial software ANSYS 8.0
(Canonsburg, PA). Three-dimensional surface models of the screws were first generated by helical sweep of a predetermined thread with Ansys Parametric Design Language. Then the surface models were transformed to solid models with the use of a Boolean operation. Next the screws were inserted at the center of a cylinder simulating the condition in mechanical tests (Fig. 4). The materials of the screws and cylinder were assumed to be linear isotropic. The pedicle screw and cylinder were map-meshed with 8-node hexahedral elements except the irregular contact surfaces, which were free-meshed with high order 20-node hexahedral elements. The overall element size was $0.4 \mathrm{~mm}$. Surface-to-surface contact elements with a frictional coefficient of zero were used for the interface between the pedicle screw and polyethylene. The contact surfaces of the pedicle screw were meshed with CONTA 174, and the contact surfaces of the cylinder were meshed with TARGE 170. Axial rotation of the screws was not allowed. The loading and boundary conditions were also the same as those of the mechanical tests. The solution was done with the assumption of small deformation. The numerical stability was checked by increasing mesh density, and convergence was confirmed when the variation of the

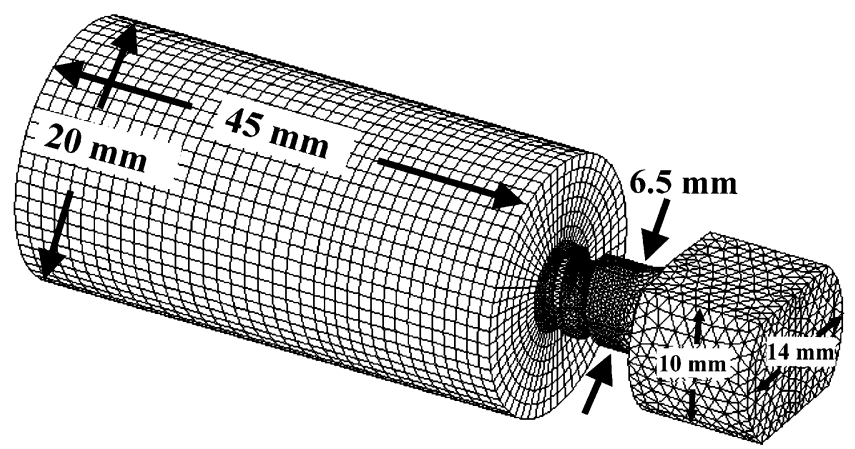

FIGURE 4. Finite element model to simulate mechanical tests. 
sequential analytical results was less than $3 \%$. The total element number ranged from 110,000 to 220,000 . The total node number ranged from 210,000 to 410,000 , and the computer solution time ranged from 12 to 28 hours.

\section{Bending Tests}

The elastic modulus was $114 \mathrm{GPa}$ for pedicle screws and $2.6 \mathrm{GPa}$ for polyethylene, and the Poisson ratio was 0.3 for both. The loading condition was a 220 or $330 \mathrm{~N}$ point load on the cylinder with a lever arm of $45 \mathrm{~mm}$. The boundary condition was full constraint around the screw head. In the postprocessing analysis, the total strain energy, maximal deflection, and maximal tensile stress of the screws were recorded. Total strain energy of the screws was defined as the sum of the strain energy of all the screw elements. Total strain energy and maximal deflection of the screws were correlated to the stiffness and yielding strength, respectively, obtained in mechanical tests. Maximal tensile stress was correlated to the fatigue life.

\section{Pullout Tests}

The elastic modulus of polyurethane foam was 137.5 and $23 \mathrm{MPa}$ for densities of 0.32 and $0.16 \mathrm{gm} / \mathrm{cm}^{3}$, respectively, and the Poisson ratio was 0.3 . The loading condition was an axial displacement of $0.01 \mathrm{~mm}$ applied to the end surface of the pedicle screw, and the boundary condition was full constraint at the surface of the cylinder. For screws with a conical core, the foam compaction effects were simulated by adjusting the elastic modulus of the bone surrounding the conical core according to the density change of the bone around that core. ${ }^{16}$ Density change was calculated on the basis of the volume reduction caused by the conical core. The elastic modulus of bone was assumed to be a power-law function of the density with an exponent of 2 . In the postprocessing analysis, the total reaction force on screws, defined as the summation of the resultant axial force on the nodes over the end surface of the screw with preapplied displacement, and the total strain energy of foams, defined as the sum of the strain energy of all the foam elements, were recorded. The total reaction force and the total strain energy were correlated to the pullout strength obtained in the mechanical tests.

\section{Statistical Methods}

Analysis of variance was used to compare the differences of the bending strength and pullout strength among these 10 pedicle screws. The least-significant difference test was used for post hoc comparison. The results of mechanical tests were correlated to finite element analyses with linear regression analysis. The level of significant difference was defined as $P<0.05$.

\section{RESULTS}

\section{Mechanical Tests}

\section{Bending Tests}

In the single-loading tests, all of the screws failed at the region around the thread-shank junction. In the load deformation curves, the curve rose up rapidly at the beginning and became horizontal when the loading continued (Fig. 5A). The curve dropped down only in type I-4 screws, which had cracked at the thread valley
FIGURE 5. Load-deformation curve in single-loading tests (A) and deformationcycle curve in cyclic-loading tests (B).
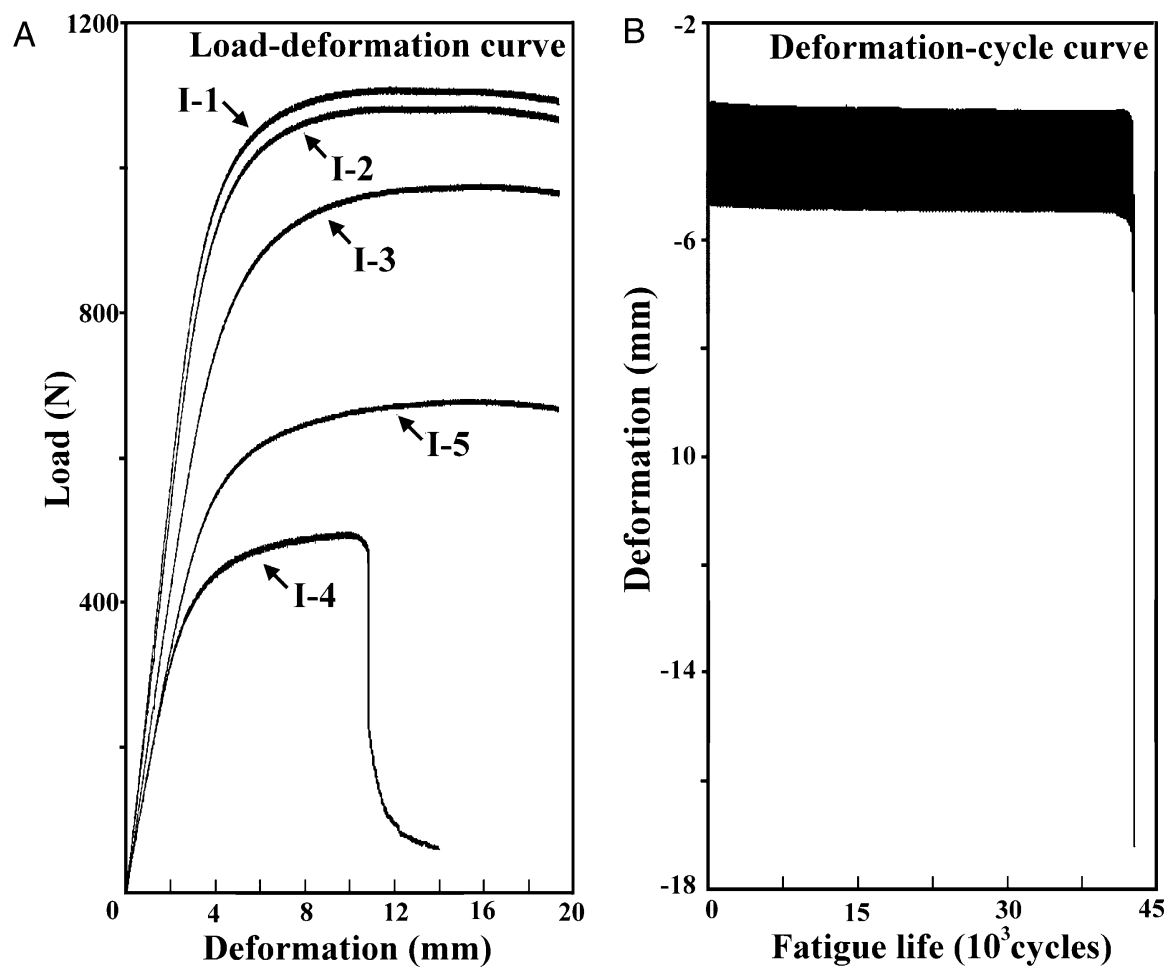
because of the stress concentration effect. The curve kept horizontal throughout the tests in the other screws with plastic deformation. The stiffness was defined as the maximal slope of the initial linear part of the curve, and $0.2 \%$ offset yielding strength was defined according to ASTM F1717-96 22 (Table 2). The stiffness was in parallel with the yielding strength with the correlation coefficient of $0.98(P<0.01)$. The screws with longer conical cores or larger core diameters had significantly higher stiffness and yielding strength $(P<0.01$ for both groups I and II) (Fig. 6). In the cyclic-loading tests, the screws deformed steadily during loading (Fig. 5B). The failure end point was defined as the point at which the deformation abruptly increased and the screws cracked. The cyclic stiffness, defined as the average of 500 cycles at the steady state, was closely related to the single load stiffness ( $r=0.98$ for both loadings, $P<0.01$ ), but it had a smaller standard deviation and higher value. The screws with a conical core or a larger core diameter or without the step at proximal thread-shank junction had significantly longer fatigue life $(P<0.01$ for both 400 and $600 \mathrm{~N}$ loading) (Fig. 7). For $400 \mathrm{~N}$ loading, all the type I-4 and I-5 screws and 1 type II-4 screw cracked. Other screws sustained $10^{6}$ cycles without any deformation. In $600 \mathrm{~N}$ loading, type I-4 was not tested because of too low strength. In addition to type I-5 and II-4, type I-3 and type II-5 also failed. The screws always cracked at the thread-shank junction except for type I-3, which cracked at the third or fourth thread. No plastic deformation of the screws was observed. The deformation of the highmolecular-weight polyethylene cylinders with a small bending moment was grossly invisible and negligible in both yielding and cyclic loading tests.

\section{Pullout Tests}

As the screws were extracted, the load increased sharply and then dropped rapidly (Fig. 8) when the screw stripped the polyurethane foam. Screw displacement at the point of peak load was within 2 pitches in all the screws, and the peak load was defined as the pullout strength. The screw structure was completely preserved after pullout. The pullout strength of both screw groups was consistently higher in the foams with a higher density $(P<0.01)$ (Table 2) (Fig. 9). The pullout strength of group I screws was significantly higher than that of group II screws in either 0.32 or $0.16 \mathrm{gm} / \mathrm{cm}^{3}$ polyurethane foams with an average increase of $26 \%$ and $25 \%$, respectively $(P<0.01)$. However, only in the foam with a density of $0.32 \mathrm{gm} / \mathrm{cm}^{3}$ were the pullout strengths of type I-1, I-2, and I-3 each significantly higher when compared with that of type I-4 $(P<0.01$ for the respective comparisons) with an average increase of only $6.4 \%$. By contrast, the pullout strength was not significantly different among group I screws in the foam with $0.16 \mathrm{gm} / \mathrm{cm}^{3}$, nor did it differ significantly among the group II screws in either of the foams.

\section{Finite Element Analysis}

When the solutions reached convergence, the relationship between the maximal deflection and total

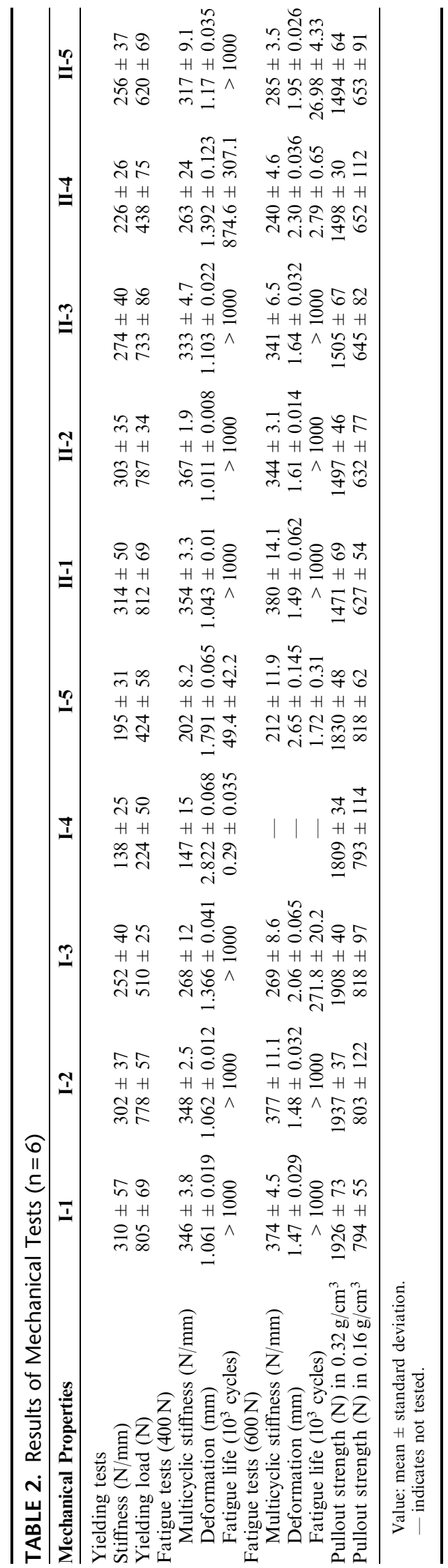




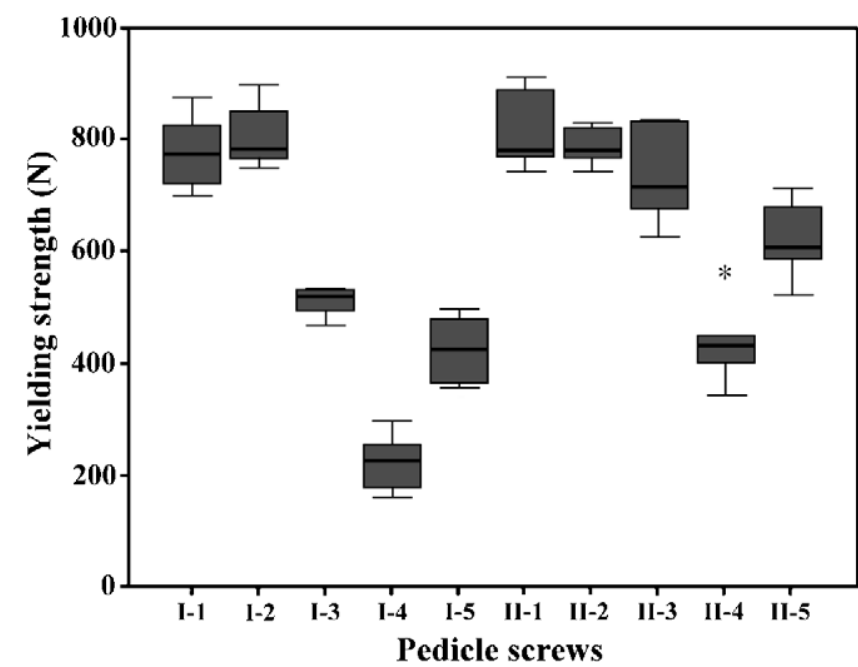

FIGURE 6. Box and whisker plots of the yielding strength of single-loading tests. The difference reached significant level in all pairs except I- 1 versus I-2, II- 1 versus II-2, and II-2 versus II-3. Asterisks represent outliers.

strain energy in bending analyses and between the total reaction force and total strain energy in pullout analyses was almost linear $(r=0.99$ for both, $P<0.01)$ (Table 3$)$. In bending analyses, the maximal deflection was closely related to the stiffness and yielding strength measured in

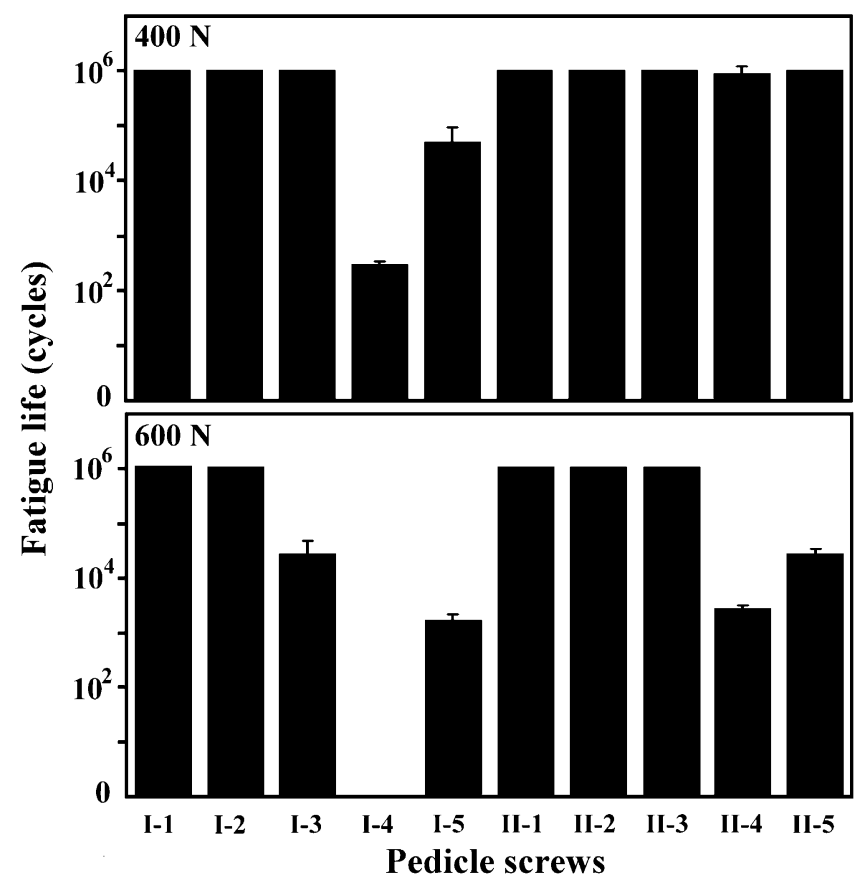

FIGURE 7. Fatigue life under different loading. The fatigue life of the conical screws without step was significantly longer than that of the cylindrical screws and conical screws with step. For conical screws without step in $600 \mathrm{~N}$ loading, the fatigue life of type I-1 and I-2 was significantly longer than that of type I-3.

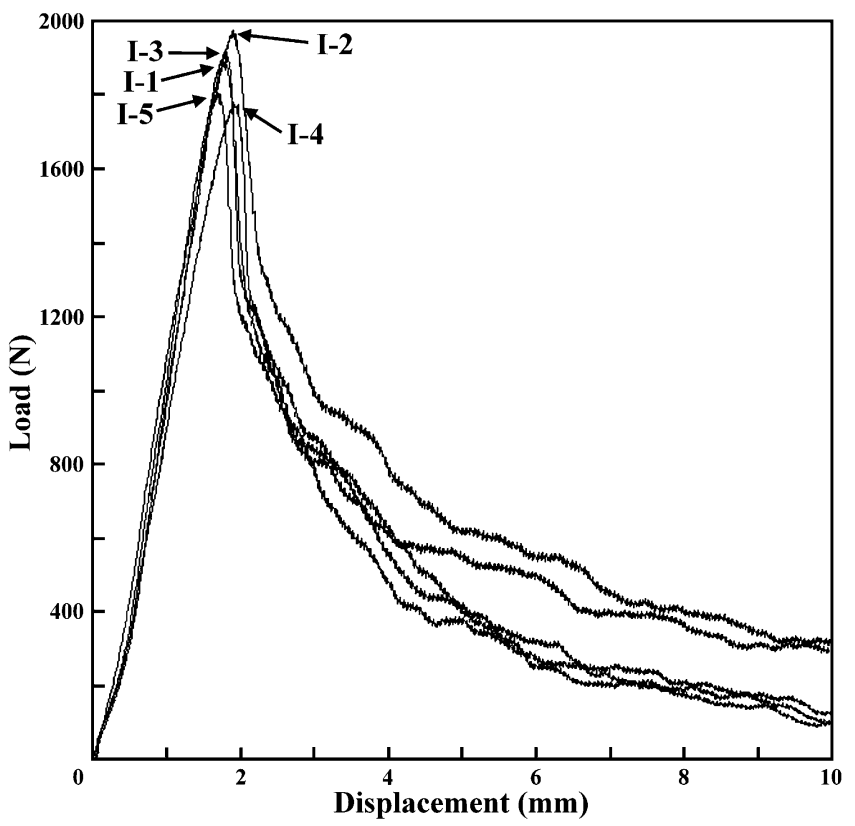

FIGURE 8. Load-deformation curve in pullout tests.

the mechanical tests $(r=-0.95$ and -0.91 , respectively, $P<0.01)$. The maximal tensile stress was closely related to the logarithm of fatigue life $(r=-0.95, P<0.01$ for both 400 and $600 \mathrm{~N}$ loading). The point with maximal tensile stress corresponded to the failure site in mechanical tests (Fig. 10). In pullout analyses, the deformation of the screws was negligible $(<0.1 \%)$, a finding compatible with that of the mechanical tests. The total reaction force was closely related to the pullout strength measured in the

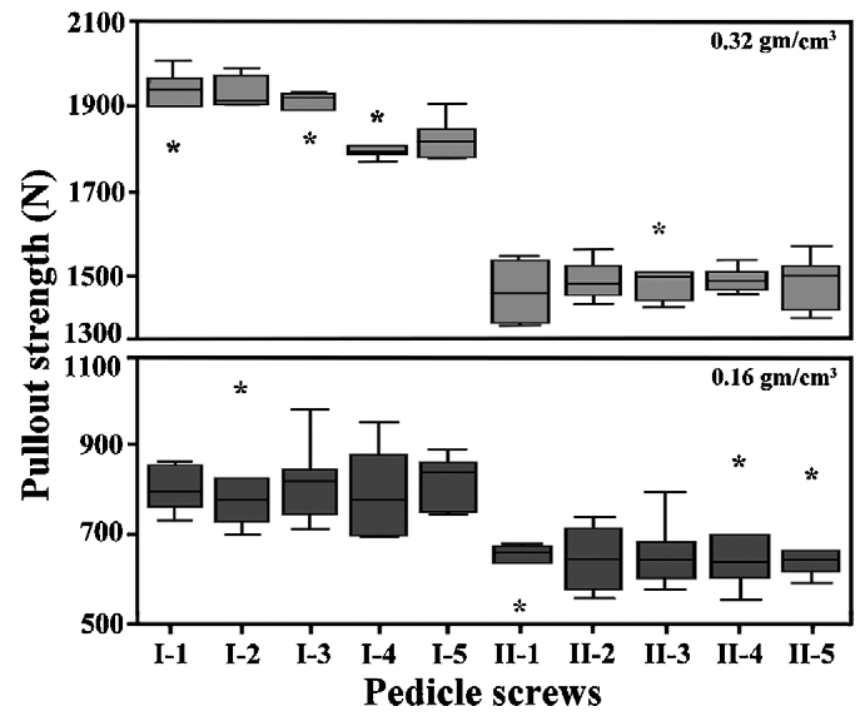

FIGURE 9. Box and whisker plots of the pullout strength of pullout tests. The difference reached significant level in $1-1$ versus $\mathrm{I}-4$, $\mathrm{I}-1$ versus $\mathrm{I}-5, \mathrm{I}-2$ versus $\mathrm{I}-4, \mathrm{I}-2$ versus $\mathrm{I}-5$, $\mathrm{I}-3$ versus $\mathrm{I}-4$, and $\mathrm{I}-3$ versus $\mathrm{I}-5$ in the foam with a density of $0.32 \mathrm{gm} / \mathrm{cm}^{3}$. Asterisks represent outliers. 


\begin{tabular}{|c|c|c|c|c|c|c|c|c|c|c|}
\hline Mechanical Properties & I-1 & $\mathbf{I}-2$ & $\mathbf{I}-3$ & I-4 & $\mathrm{I}-5$ & II-1 & III-2 & III-3 & II-4 & II-5 \\
\hline \multicolumn{11}{|l|}{ Bending tests $(220 \mathrm{~N})$} \\
\hline Total strain energy $(\mathrm{J})$ & 50 & 53 & 61 & 138 & 86 & 49 & 51 & 56 & 82 & 65 \\
\hline Maximal tensile stress (MPa) & 387 & 419 & 512 & 1684 & 863 & 345 & 373 & 431 & 891 & 599 \\
\hline \multicolumn{11}{|l|}{ Bending tests $(330 \mathrm{~N})$} \\
\hline Maximal deflection (mm) & 0.903 & 0.951 & 1.112 & 2.522 & 1.551 & 0.884 & 0.913 & 1.015 & 1.478 & 1.168 \\
\hline \multicolumn{11}{|l|}{ Pullout tests $\left(0.32 \mathrm{~g} / \mathrm{cm}^{3}\right)$} \\
\hline Total strain energy $(\mathrm{mJ})$ & 181.8 & 184.0 & 185.2 & 178.7 & 185.0 & 164.0 & 166.2 & 170.1 & 175.5 & 176.6 \\
\hline Total reaction force $(\mathrm{N})$ & 36.77 & 37.26 & 37.48 & 36.29 & 37.47 & 33.51 & 33.99 & 34.71 & 35.79 & 36.06 \\
\hline \multicolumn{11}{|l|}{ Pullout tests $\left(0.16 \mathrm{~g} / \mathrm{cm}^{3}\right)$} \\
\hline Total strain energy $(\mathrm{mJ})$ & 30.95 & 31.31 & 31.53 & 30.45 & 31.51 & 27.96 & 28.32 & 28.94 & 29.74 & 30.02 \\
\hline Total reaction force $(\mathrm{N})$ & 6.26 & 6.34 & 6.38 & 6.18 & 6.38 & 5.71 & 5.79 & 5.90 & 6.07 & 6.13 \\
\hline
\end{tabular}

mechanical tests $\left(r=0.84\right.$ with $0.32 \mathrm{gm} / \mathrm{cm}^{3}$ and 0.91 with $\left.16 \mathrm{gm} / \mathrm{cm}^{3}, P<0.01\right)$.

\section{DISCUSSION}

The transpedicle screw device has facilitated shortsegment instrumentation for fractures, and spondylolisthesis and has made total vertebrectomy for neoplasms practical. ${ }^{4,23}$ Short-segment instrumentation involving only one level above and below the diseased vertebra can preserve more motion segments and avoid the disadvantages of long-segment instrumentation, which increases load at the adjacent segments ${ }^{24}$ and leads to accelerated arthritis in the immobilized but unfused segments and increased prevalence of late back pain. ${ }^{3}$ However, transpedicle screw instrumentation has not been free of complications. ${ }^{23}$ Screw breakage, which is

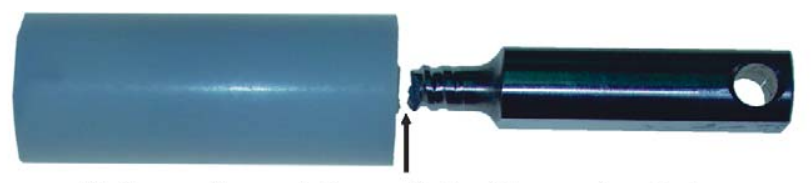

Failure site and the point with maximal stress
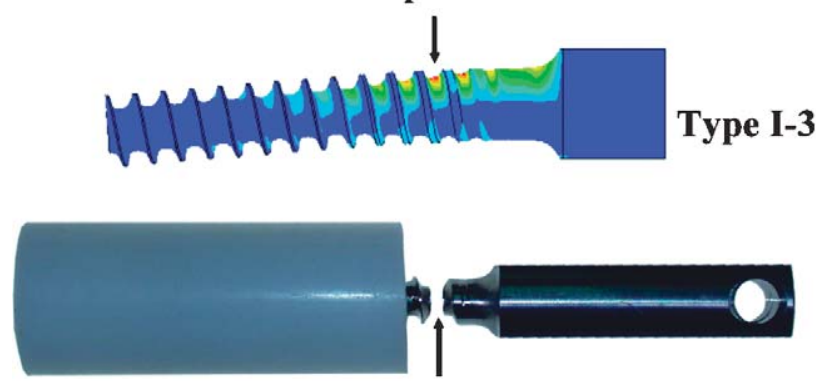

Failure site and the point with maximal stress

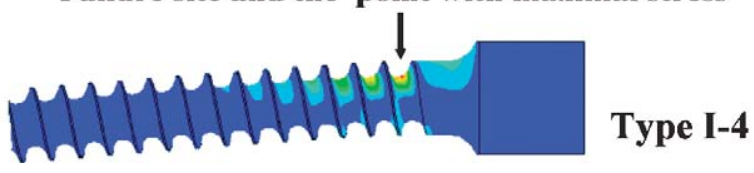

FIGURE 10. Failure site of the screws corresponding to the points with maximal tensile stress in finite element analyses. much more common than rod breakage, tends to happen in fixation of bursting fractures, ${ }^{8,23}$ multiple level fusion, or fusion extending to the sacral area. ${ }^{2,6}$ Severe osteoporosis may further predispose the screw to loosen. ${ }^{13,16,25,26}$ The rate of implant failure, ranging from $2.6 \%$ to as high as $60 \%,{ }^{3}$ necessitates combined anterior strut-grafting and instrumentation. ${ }^{23}$ The anterior approach, however, is associated with a long operation time and high operative morbidity, especially in elderly patients with a fragile medical status. ${ }^{27,28}$ Consequently, transpedicular vertebroplasty with bone graft, ${ }^{29}$ bone cement, ${ }^{10}$ or body augmenter ${ }^{27}$ has been reported, but these methods may be ineffective ${ }^{8}$ or threatened by dural sac injury ${ }^{28}$ or adverse effects of bone cement. ${ }^{26,30}$

Many mechanical studies have been conducted to investigate the mechanical performance of the transpedical screw-based systems. ${ }^{16,18}$ However, these studies have flaws. First, the entire system was tested even though the system was composed of components with different geometries and dimensions or had different intended uses, such as for scoliosis or a degenerative spine. , $^{91-34}$ The varied stiffness and failure pattern might lead to misjudgments about the component's strength. Second, the structures of the tested components were not adequately controlled. ${ }^{13,14,33,35}$ The comparisons might be based on different baselines and thus lead to biased conclusions about the design. Third, because the geometries and dimensions were not sufficiently described, $, 9,33,36$ it is difficult to analyze the results of the mechanical tests, especially when manufacturers may have produced more than one generation of a screw. Fourth, the loading on each screw was different in the fatigue tests, ${ }^{34}$ leading to complexity in comparing the strength among the tested screws. Fifth, only bending strength or pullout strength was assessed. ${ }^{11,12,18}$ Considering only one objective might lead to inadequacy in the other because these 2 objectives might conflict with each other. In the present study, the design variables of the screws were well controlled, and the geometry and dimensions were addressed in detail. The testing load was kept constant. The 2 mechanical performances were considered simultaneously. 
Higher stiffness and mechanical strength is believed to be beneficial for spinal fusion and maintenance of reduction. In the present study, conical screws achieved markedly higher yielding strength and fatigue life than cylindrical screws. The longer the conical core was, the stronger the screws were. In cyclic loading, cyclic stiffness, which was higher than single load stiffness because of a faster loading rate, had a smaller variation and could be reliably used for comparison among different screws. ${ }^{18}$ As found by Cunningham et al, ${ }^{32}$ different fixators with similar dimensions might have great variation of mechanical properties, especially fatigue strength. This finding emphasizes the importance of screw design. For type I-5 and II-5 screws, the residual step at the thread-shank junction might induce significant stress concentration and jeopardize the fatigue strength. The fatigue life of implants is substantially affected by the applied load. In previous studies, loading ranging from 400 to $1000 \mathrm{~N}$ was used for fatigue testing of the whole set of bone-implant constructs, that is, 4 pedicle screws and 2 rods on 2 plastic wafers. ${ }^{9,18,32,34,36}$ In the present study, the 400 and $600 \mathrm{~N}$ used for fatigue testing of the single screw were equivalent to 800 and $1200 \mathrm{~N}$ on the whole set of bone-implant constructs. This high load simulated a worst-case scenario such as the unstable bursting fractures without anterior support.

The reported contradictory results in comparisons of the pullout strength of conical screws and cylindrical screws could be attributed to variations in bone quality, screw-cortical interface, and screw structures responsible for bone purchase. Artificial foam with its more consistent properties could prevent the bias caused by the variation of bone quality and screw-cortical interface. ${ }^{16}$ Careful control of design variables could prevent the bias of structural incomparability. Theoretically, the conical core can compact the surrounding bone and increase the pullout strength, ${ }^{12}$ but it may lower the pullout strength because of the decreased thread depth. Consequently, the pullout strength of the conical screws was actually a trade-off between the positive effects of bone compaction and the negative effects of decreased thread depth. The present study found that conical screws could significantly increase the pullout strength as compared with cylindrical screws by about $6.4 \%$ in $0.32 \mathrm{gm} / \mathrm{cm}^{3}$ polyurethane foam. However, this increase was not significant in situations with lower foam density or larger core diameter. These findings may help explain the pullout strength discrepancies in the literature. Nevertheless, the much higher pullout strength in group I screws than in group II screws in both foams $(26 \%$ and $25 \%$, respectively) implies that the core diameter may contribute more to the pullout strength than does conical core design.

Finite element analysis, a convenient and speedy tool for solving a wide variety of complicated engineering problems, can be applied to studies of pedicle screws with irregular thread patterns or core diameter. ${ }^{16}$ It can appreciably save the expense, time, and effort of repeated mechanical tests during development of new designs. The finite element analysis incorporates all the factors involved in the problem and also allows investigation of the effects of an individual factor independently by means of sensitivity analysis. In this study, the failure pattern observed in mechanical tests corresponded to the findings in finite element analyses. The linear relationships between the total strain energy and the maximal deflection in bending analysis and between the total strain energy and total reaction force in pullout analysis were compatible with the linear part of the loaddisplacement curve in the mechanical tests. The close relationship between the results of finite element analyses and those of mechanical tests support the use of the finite element models to predict the bending strength and pullout strength of pedicle screws before manufacturing or clinical use.

The limitations of the present study should be addressed. This is an in vitro study. The conditions in a real human body are subject to changes of screw structures, material properties of the bone and screws, interface properties between the bone and screws, loading condition, boundary condition, and loading rate in the patient. Still, the results obtained in this study mainly reflect the relative scales among the screws that were minimally affected by the aforementioned factors and are useful for comparative studies. Furthermore, besides pedicle screws, other components such as the rod, rodscrew clamp, cross-linking device, and screw-bone interface could also affect the rigidity and strength of the spinal fixation.

In conclusion, the present study supported the hypotheses that conical screws yield significantly higher bending strength and pullout strength simultaneously than do cylindrical screws. The finite element models developed in this study reliably predict the mechanical performance of the pedicle screws and can be used for multiobjective optimization studies for the optimal screw design. ${ }^{37}$ The findings of this study can assist manufacturers design better implants and help surgeons select suitable devices for their patients.

\section{REFERENCES}

1. Katonis $\mathrm{P}$, Christoforakis J, Aligizakis CA, et al. Complications and problems related to pedicle screw fixation of the spine. Clin Orthop. 2003;411:86-94.

2. Pihlajamaki H, Myllynen P, Bostman O. Complications of transpedicular lumbosacral fixation for non-traumatic disorders. J Bone Joint Surg Br. 1997;79:183-189.

3. Vaccaro AR, Kim DH, Brodke DS, et al. Diagnosis and management of thoracolumbar spine fractures. J Bone Joint Surg Am. 2003; 85:2456-2470.

4. Sanderson PL, Fraser RD, Hall DJ, et al. Short segment fixation of thoracolumbar burst fractures without fusion. Euro Spine J. 1999;8: 495-500.

5. Katonis PG, Kontakis GM, Loupasis GA, et al. Treatment of unstable thoracolumbar and lumbar spine injuries using CotrelDubousset instrumentation. Spine. 1999;24:2352-2357.

6. Jutte PC, Castelein RM. Complications of pedicle screws in lumbar and lumbosacral fusions in 105 consecutive primary operations. Euro Spine J. 2002;11:594-598.

7. Lonstein JE, Denis F, Perra JH, et al. Complications associated with pedicle screws. J Bone Joint Surg Am. 1999;81:1519-1528. 
8. Alvine GF, Swain JM, Asher MA, et al. Treatment of thoracolumbar burst fractures with variable screw placement or Isola instrumentation and arthrodesis: case series and literature review. J Spinal Disord Tech. 2004;17:251-264.

9. Stambough JL, Khatib FE, Genaidy AM, et al. Strength and fatigue resistance of thoracolumbar spinal implant: a experimental study of selected clinical devices. J Spinal Disord. 1999;12:410-414.

10. Cho DY, Lee WY, Sheu PC. Treatment of thoracolumbar burst fractures with polymethyl methacrylate vertebroplasty and shortsegment pedicle screw fixation. Neurosurg. 2003;53:1354-1361.

11. Vanichkachorn JS, Vaccaro A, Cohen MJ, et al. Potential large vessel Injury during thoracolumbar pedicle screw removal: a case report. Spine. 1997;22:110-113.

12. Abshire BB, McLain RF, Valdevit A, et al. Characteristics of pullout failure in conical and cylindrical pedicle screws after full insertion and back-out. The Spine J. 2001;1:408-414.

13. Kwok AWL, Finkelstein JA, Woodside T, et al. Insertional torque and pull-out strengths of conical and cylindrical pedicle screws in cadaveric bone. Spine. 1996;21:2429-2434.

14. Lill CA, Schlegel U, Wahl D, et al. Comparison of the in vitro holding strengths of conical and cylindrical pedicle screws in a fully inserted setting and backed out $180^{\circ}$. J Spinal Disord. 2000;13: 259-266.

15. Ono A, Brown MD, Latta LL, et al. Triangulated pedicle screw construct technique and pull-out strength of conical and cylindrical screws. J Spinal Disord. 2001;14:323-329.

16. Hsu CC, Chao CK, Wang JL, et al. Increase of pullout strength of spinal pedicle screws with conical core: biomechanical tests and finite element analyses. J Orthop Res. 2005;23:788-794.

17. Allen RF, Baldini NC, Donofrio PE, et al. Standard Specification for Wrought Titanium-6 Aluminum-4 Vanadium ELI (Extra Low Interstitial) Alloy for Surgical Implant Applications (F136-96). Annual Book of ASTM Standards, Medical Devices and Services. West Conshohocken: The American Society for Testing and Materials; 1998.

18. Chen PQ, Lin SJ, Wu SS, et al. Mechanical performance of the new posterior spinal implant: effect of materials, connecting plate, and pedicle screw design. Spine. 2003;9:881-887.

19. Fogel GR, Reitman CA, Liu W, et al. Physical characteristics of polyaxial-headed pedicle screws and biomechanical comparison of load with their failure. Spine. 2003;28:470-473.

20. Allen RF, Baldini NC, Donofrio PE, et al. Standard Specification for Rigid Polyurethane Foam for Use as a Standard Material for Testing Orthopedic Devices and Instruments (F1839-97). West Conshohocken: The American Society for Testing and Materials; 1998

21. Allen RF, Baldini NC, Donofrio PE, et al. Standard Test Method for Determining Axial Pull-out Strength of Medical Bone Screws (F1691-96). Annual Book of ASTM Standards, Medical Devices and Services. West Conshohocken: The American Society for Testing and Materials; 1998

22. Allen RF, Baldini NC, Donofrio PE, et al. Standard Test Method for Static and Fatigue for Spinal Implant Constructs in a Corpectomy
Model (F1717-96). Annual Book of ASTM Standards, Medical Devices and Services. West Conshohocken: The American Society for Testing and Materials; 1998

23. Gaines RW. The use of pedicle-screw internal fixation for the operative treatment of spinal disorders. J Bone Joint Surg Am. 2000;82:1458-1476.

24. Parker JW, Lane JR, Karaikovic EE, et al. Successful short-segment instrumentation and fusion for thoracolumbar spine fractures. A consecutive 4.5-year series. Spine. 2000;25:1157-1169.

25. Okuyama K, Abe E, Suzuki T, et al. Influence of bone mineral density on pedicle screw fixation: a study of pedicle screw fixation augmenting posterior lumbar interbody fusion in elderly patients. The Spine J. 2001;1:402-407.

26. Renner SM, Lim TH, Kim WJ, et al. Augmentation of pedicle screw fixation strength using an injectable calcium phosphate cement as a function of injection timing and method. Spine. 2004;29: E212-E216.

27. Chen HH, Wang WK, Li KC, et al. Biomechanical effects of the body augmenter for reconstruction of the vertebral body. Spine. 2004;29:E384-E387.

28. Kaya RA, Aydin Y. Modified transpedicular approach for the surgical treatment of severe thoracolumbar or lumbar burst fractures. The Spine J. 2004:4:208-217.

29. Alanay A, Acaroglu E, Yazici M, et al. Short-segment pedicle instrumentation of thoracolumbar burst fractures. Does transpedicular intracorporeal grafting prevent early failure? Spine. 2001;26: 213-217.

30. Acosta FL, Aryan HE, Taylor WR, et al. Kyphoplasty-augmented short-segment pedicle screw fixation of traumatic lumbar burst fractures: initial clinical experience and literature review. Neurosurg Focus. 2005;18:1-6.

31. Ashman RB, Galpin RD, Corin JD, et al. Biomechanical analysis of pedicle screw instrumentation system in a corpectomy model. Spine. 1989;14:1398-1405.

32. Cunningham BW, Sefter JC, Shono Y, et al. Static and cyclic biomechanical analysis of pedicle screw spinal constructs. Spine. 1993;18:1677-1688.

33. Pienkowski D, Stephens G, Doers TM, et al. Multicycle mechanical performance of titanium and stainless steel transpedicular spine implants. Spine. 1998;23:782-788.

34. Stanford RE, Loefler AH, Stanford PM, et al. Multiaxial pedicle screw designs: static and dynamic mechanical testing. Spine. 2004;29:367-375.

35. Moran JM, Berg WS, Berry JL, et al. Transpedicular screw fixation. J Orthop Res. 1989;7:107-114.

36. Stambough JL, Genaidy AM, Huston RL, et al. Biomechanical assessment of titanium and stainless steel posterior spinal constructs: effects of absolute/relative loading and frequency on fatigue life and determination of failure modes. J Spinal Disord. 1997;10: 473-481.

37. Hsu CC, Chao CK, Wang JL, et al. Multiobjective optimization of tibial locking screws design using a genetic algorithm: evaluation of mechanical performance. J Orthop Res. 2006;24:908-916. 